\title{
Risk of Surgery for Congenital Heart Disease in the Adult: A Multicentered European Study
}

\author{
Vladimiro L. Vida, MD, Hakan Berggren, MD, William J. Brawn, MD, \\ Willem Daenen, MD, Duccio Di Carlo, MD, Roberto Di Donato, MD, \\ Harald L. Lindberg, MD, Antonio F. Corno, MD, Jose Fragata, MD, \\ Martin J. Elliott, MD, Viktor Hraska, MD, Lazlo Kiraly, MD, \\ François Lacour-Gayet, MD, Bohdan Maruszewski, MD, Jean Rubay, MD, \\ Heikki Sairanen, MD, George Sarris, MD, Andreas Urban, MD, \\ Carin Van Doorn, MD, Gerhard Ziemer, MD, and Giovanni Stellin, MD
}

\begin{abstract}
Pediatric Cardiac Surgery Unit, University of Padova, Padova, Italy; The Queen Silvia Children's Hospital, Goteborg, Sweden; Birmingham Children's Hospital, Birmingham, United Kingdom; Gasthuisberg Universitair Ziekenhuis, Leuven, Belgium; Ospedale Pediatrico Bambino Gesu, Rome, Italy; Rikshospitalet, The National Hospital, Oslo, Norway; Centre Hospitalier Universitaire Vaudois, Lausanne, Switzerland; Hospital de Santa Marta, Lisbon, Portugal; The Cardiac Unit, The Great Ormond Street Hospital for Children, London, United Kingdom; Children's Hospital, Bratislava, Slovakia; Gottsegen Gyorgy Orszagos Kardiologiai Intezet, Gyermeksziv Kozpont, Budapest, Hungary; Eppendorf University Hospital, Hamburg, Germany; The Children's Memorial Health Institute, Warsaw, Poland; Cliniques Universitaires Saint-Luc, Brussels, Belgium; Hospital for Children and Adolescents, University of Helsinki, Helsinki, Finland; Onassis Cardiac Surgery Center, Athens, Greece; Deutsches Kinderherzzentrum, St. Augustin, Germany; Yorkshire Heart Centre, Leeds General Infirmary, Leeds, United Kingdom; and Eberhad Karls Universitat, Tubingen, Germany
\end{abstract}

Background. Surgery for congenital heart disease (CHD) has changed considerably during the last three decades. The results of primary repair have steadily improved, to allow treating almost all patients within the pediatric age; nonetheless an increasing population of adult patients requires surgical treatment. The objective of this study is to present the early surgical results of patients who require surgery for $\mathrm{CHD}$ in the adult population within a multicentered European study population.

Methods. Data relative to the hospital course of 2,012 adult patients (age $\geq 18$ years) who required surgical treatment for CHD from January 1, 1997 through December 31, 2004 were reviewed. Nineteen cardiothoracic centers from 13 European countries contributed to the data collection.

Results. Mean age at surgery was $34.4 \pm 14.53$ years. Most of the operations were corrective procedures $(1,509$ patients, $75 \%$ ), followed by reoperations (464 patients,

S urgery for congenital heart disease (CHD) has changed considerably during the last three decades. The results of primary repair of CHD have steadily improved and allowed to treat almost all patients within the pediatric age group. This was in part due to a more widespread screening of asymptomatic patients and to the optimization of the results of early correction in neonates and infants. Nonetheless, an increasing population of adult patients requires surgical treatment for CHD. This selected

Accepted for publication July 21, 2006.

Address correpondence to Dr Stellin, Department of Cardiovascular Surgery, Pediatric Cardiac Surgery Unit, Via Giustiniani, 2-35128 Padova, Italy; e-mail: giovanni.stellin@unipd.it.
$23.1 \%$ ) and palliative procedures (39 patients, $1.9 \%$ ). Six hundred forty-nine patients $(32.2 \%)$ required surgical closure of an isolated ostium secundum atrial septal defect. Overall hospital mortality was $2 \%$. Preoperative cyanosis, arrhythmias, and NYHA class III-IV, proved significant risk factors for hospital mortality. Follow-up data were available in 1,342 of 1,972 patients $(68 \%)$ who were discharged home. Late deaths occurred in 6 patients $(0.5 \%)$. Overall survival probability was $97 \%$ at 60 months, which is higher for corrective procedures (98.2\%) if compared with reoperations $(94.1 \%)$ and palliations $(86.1 \%)$.

Conclusions. Surgical treatment of CHD in adult patients, in specialized cardiac units, proved quite safe, beneficial, and low-risk.

(Ann Thorac Surg 2007;83:161-8) (C) 2007 by The Society of Thoracic Surgeons recognized $\mathrm{CHD}$ who have survived into adult age without any surgical treatment and without developing an irreversible damage to their heart and lungs; (2) patients who are candidates for correction after previous palliative procedures; (3) adult patients who either require reoperations because of late complications or residual defects; (4) patients who require additional palliative procedures or even heart transplantation [1-4], and (5) patients with previously undetected CHD who remained asymptomatic during childhood. Ostium secundum atrial septal defects (ASD II) provide the best example of CHD within this last group of patients [4-6]. The majority of the latter patients usually maintain a good or only mildly decreased functional status 
Table 1. Main "Basic Diagnoses" Total Number of Patients $=2,012$ )

\begin{tabular}{|c|c|c|c|}
\hline Diagnosis Category & $\mathrm{n}$ & Diagnosis Type & $\mathrm{n}$ \\
\hline \multirow[t]{5}{*}{ Septal defects } & 895 & ASD (ostium secundum and sino venosus types) & 649 \\
\hline & & Partial AVSD & 119 \\
\hline & & VSD & 108 \\
\hline & & Complete AVSD & 12 \\
\hline & & Truncus arteriosus & 7 \\
\hline \multirow[t]{4}{*}{ Pulmonary venous anomalies } & 108 & PAPVC & 93 \\
\hline & & TAPVC & 7 \\
\hline & & Pulmonary venous stenosis & 4 \\
\hline & & Cor triatriatum & 4 \\
\hline Systemic venous anomalies & 5 & Anomalous connections/obstruction & 5 \\
\hline \multirow[t]{8}{*}{ Right heart lesions } & 420 & TOF & 219 \\
\hline & & TOF-PA & 70 \\
\hline & & RVOT obstruction & 33 \\
\hline & & Pulmonary valve stenosis & 27 \\
\hline & & Ebstein's tricuspid valve & 27 \\
\hline & & TV stenosis/regurgitation non-Ebstein related & 20 \\
\hline & & Pulmonary valve regurgitation & 18 \\
\hline & & PA-IVS & 6 \\
\hline \multirow[t]{6}{*}{ Left heart lesions } & 311 & Congenital aortic valve stenosis & 88 \\
\hline & & Congenital aortic valve stenosis + regurgitation & 63 \\
\hline & & Subaortic fibrous stenosis & 56 \\
\hline & & Congenital aortic valve regurgitation & 50 \\
\hline & & Congenital mitral valve stenosis/regurgitation & 37 \\
\hline & & Other & 17 \\
\hline \multirow[t]{2}{*}{ Single ventricle } & 70 & Single right ventricle & 58 \\
\hline & & Single left ventricle & 12 \\
\hline \multirow[t]{3}{*}{ Transposition of the great arteries } & 73 & Congenitally corrected TGA & 35 \\
\hline & & Complete TGA-VSD & 22 \\
\hline & & Complete TGA-IVS & 16 \\
\hline \multirow[t]{3}{*}{ Double outlet right ventricle } & 16 & TOF type & 10 \\
\hline & & Uncommitted VSD type & 5 \\
\hline & & TGA type & 1 \\
\hline \multirow[t]{4}{*}{ Thoracic arteries and veins } & 101 & Isthmic aortic coarctation & 69 \\
\hline & & Coronary artery anomalies & 12 \\
\hline & & Patent ductus arteriosus & 10 \\
\hline & & Vascular ring & 5 \\
\hline Electrophysiology & 5 & Congenital III degree AV block & 5 \\
\hline \multirow[t]{2}{*}{ Miscellaneous } & 8 & Cardiac tumor & 3 \\
\hline & & Other & 5 \\
\hline
\end{tabular}

ASD II = ostium secundum atrial septal defect; $\quad$ AV = atrioventricular; $\quad$ AVSD = atrioventricular septal defects; $\quad$ IVS = interventricular septum; $\quad \mathrm{PA}=$ pulmonary atresia; $\quad \mathrm{PAPVC}=$ partial anomalous pulmonary venous connections; $\mathrm{RVOT}=$ right ventricular outflow tract; $\quad \mathrm{TAPVC}=$ total anomalous pulmonary venous connections; $\quad$ TGA = transposition of the great arteries; $\quad$ TOF = tetralogy of Fallot; $\quad$ VSD = ventricular septal defect.

for several years and generally are referred for surgical closure of the ASD II because of increasing symptoms not controlled by medical therapy [7-9]. The objective of this study is to present the early surgical results of patients who require surgery for $\mathrm{CHD}$ in the adult population within a multicentered European study population.

\section{Material and Methods}

Data were reviewed retrospectively relative to the hospital course of adult patients ( $\geq 18$ years) who required surgical treatment of CHD from January 1, 1997 through December 31, 2004. Nineteen cardiothoracic centres from 13 European Countries contributed initially to the data collection.

Individual consent was not obtained by patients enrolled in this study. However, this is a retrospective study, patients are not identified, and the chairperson of each Ethics Committee approved to send their data with the aim of publication. This study was undertaken under the aegis of the European Congenital Heart Surgeons Association. Previous multicentered studies have already 
Table 2. Main Diagnoses Leading to Surgery Listed According to the Operative Surgical Category

\begin{tabular}{|c|c|}
\hline \multicolumn{2}{|c|}{ Main diagnoses leading to palliative procedure $(n=39)$} \\
\hline Single ventricle & $17(53.1 \%)$ \\
\hline TOF-PA & $10(28.1 \%)$ \\
\hline Corrected TGA & $6(9.5 \%)$ \\
\hline Ebstein's tricuspid valve & $2(6.2 \%)$ \\
\hline Other & $4(3.1 \%)$ \\
\hline \multicolumn{2}{|c|}{ Main diagnoses leading to corrective procedures $(n=1509)$} \\
\hline Isolated ASD II & $649(43.0 \%)$ \\
\hline Congenital AoV stenosis/regurgitation & $162(10.7 \%)$ \\
\hline Partial AVSD & $98(6.5 \%)$ \\
\hline VSD & $96(6.3 \%)$ \\
\hline PAPVC & $93(6.1 \%)$ \\
\hline Coarctation of the aorta & $54(3.6 \%)$ \\
\hline RVOTO & $52(3.4 \%)$ \\
\hline Subaortic stenosis & $48(3.2 \%)$ \\
\hline Single ventricle & $38(2.6 \%)$ \\
\hline Congenital MV insufficiency/stenosis & $37(2.5 \%)$ \\
\hline Tetralogy of Fallot & $37(2.5 \%)$ \\
\hline Ebstein anomaly & $19(1.3 \%)$ \\
\hline PDA & $10(0.7 \%)$ \\
\hline Supravalvar aortic stenosis & $6(0.3 \%)$ \\
\hline Other diagnoses leading to correction ${ }^{a}$ & $94(6.4 \%)$ \\
\hline \multicolumn{2}{|c|}{ Main diagnoses leading to reoperation $(n=464)$} \\
\hline Pulmonary valve insufficiency & $119(25.7 \%)$ \\
\hline Conduit failure & $79(17.0 \%)$ \\
\hline RVOTO & $56(12.1 \%)$ \\
\hline AoV insufficiency & $25(5.4 \%)$ \\
\hline Mitral valve insufficiency/stenosis & $21(4.5 \%)$ \\
\hline Residual VSD & $19(4.1 \%)$ \\
\hline Subaortic stenosis & $18(3.9 \%)$ \\
\hline Postoperative third degree AV block & $16(3.5 \%)$ \\
\hline AoV stenosis & $14(3.1 \%)$ \\
\hline Residual coarctation of the aorta & $11(2.3 \%)$ \\
\hline Prosthetic valve failure & $11(2.3 \%)$ \\
\hline Cardiomyopathy & $11(2.3 \%)$ \\
\hline Atriopulmonary connection failure & $11(2.3 \%)$ \\
\hline Tricuspid valve regurgitation & $8(1.7 \%)$ \\
\hline Obstructive pulmonary vascular disease & $2(0.4 \%)$ \\
\hline Other diagnoses leading to reoperation & $43(9.4 \%)$ \\
\hline
\end{tabular}

a Other diagnoses not listed in the table included diagnostic of single or few patients.

AoV $=$ aortic valve; $\quad$ ASD II $=$ ostium secundum atrial septal defect AVSD = atrioventricular septal defect; $\quad$ DORV = double outlet right ventricle; MAPCAs = main pulmonary artery collaterals from aorta; $\mathrm{MV}=$ mitral valve; $\quad \mathrm{PA}=$ pulmonary atresia; $\quad$ PAPVC $=$ partial anomalous pulmonary venous connections; $\quad$ PDA $=$ patent ductus arteriosus; $\quad \mathrm{PV}=$ pulmonary valve; $\quad$ RVOTO $=$ right ventricle outflow tract obstruction; TGA = transposition of the great arteries; $\mathrm{TOF}=$ tetralogy of Fallot; $\quad$ VSD $=$ ventricular septal defect.

been published under the aegis of the European Congenital Heart Surgeons Associations (ECHSA) [10, 11], which also founded the "European Congenital Database" [12-14].

Cardiac rhythm, preoperative risk factors, extra-cardiac anomalies, diagnoses leading to surgery, surgical procedures, and postoperative complications were identified according to the Pediatric European Database Classification [12-14].

For the analysis, surgical procedures were divided into three categories, including the following: (1) palliative procedures; (2) corrective procedures; and (3) reoperations. Palliative [15] procedures include all operations performed to improve the patient's clinical status, without separation between the systemic and the pulmonary circulations. Corrective procedures [15] are operations employed to achieve an anatomical or physiologic correction with separation of the pulmonary from the systemic circulation. Included in this group are also "Fontan-type" repair and "one and a half ventricle repair." Finally, reoperations refer to procedures performed after an initial correction.

Because patients requiring surgical closure of an isolated ASD II represent a large group within our adult population with CHDs, and because this operation carries a low mortality and morbidity rate, additional analysis was performed excluding the ASD II group, with the aim to better evaluate the impact of cardiac surgery on this age group of patients.

Results are presented as mean and standard deviation (median and range were used if data were not normally distributed). To assess if there was a statistical difference between the groups, data were analyzed with analysis of variance. A multiple comparison test (Tukey test) was further employed to assess statistical significance between groups. A Wilcoxon signed rank test was used to assess the change in NYHA status at follow-up of patients who were discharged from the hospital in comparison with their preoperative clinical status [16]. Level of significance was set at a $p$ value of 0.05 or less.

Overall survival probability, as well as survival probability for different surgical categories (palliative procedures, corrective procedures, and reoperation), and for patients requiring isolated ASD II closure in comparison with patients requiring surgical treatment for all other patients were analyzed according to the Kaplan-Meier method. Patients only who were discharged from the hospital and were subsequently clinically followed were entered in the probability of survival analysis.

\section{Results}

Two thousand twelve patients ( $\geq 18$ years of age) requiring surgical treatment for CHD were included in this study. Of the 2,012 patients, 1,005 were males (50\%) and 1,007 females $(50 \%)$. Mean age at surgery was $34.4 \pm 14.53$ years. Preoperative diagnosis was achieved by echocardiography in 1,225 of the 2,012 patients $(60.9 \%)$. Magnetic resonance and computer tomography of the thorax were done in addition to echocardiography as an adjunct in 647 patients $(32.1 \%)$ and cardiac catheterization 399 patients $(19.8 \%)$.

According to the preoperative clinical evaluation, 647 patients $(32.1 \%)$ belonged to New York Heart Association (NYHA) class I, 908 in NYHA class II (45.1\%), 384 in NYHA class III (19.1\%), and 73 in NYHA class IV (3.7\%).

A preoperative electrocardiogram revealed a sinus rhythm in 1,813 of 2,012 patients $(90.2 \%)$. Preoperative 
Table 3. Main Surgical Procedures, Listed Within Their Respective Surgical Categories

\begin{tabular}{|c|c|c|}
\hline Palliative procedures $(n=39)$ : & $\mathrm{n}(\%)$ & Hospital mortality - n (\%) \\
\hline Systemic-to-pulmonary shunt & $18(46.9 \%)$ & $2(11.1 \%)$ \\
\hline BCPS & $15(37.4 \%)$ & $1(6.6 \%)$ \\
\hline MAPCAs unifocalization & $3(9.5 \%)$ & - \\
\hline Pulmonary artery banding & $3(6.2 \%)$ & - \\
\hline Main corrective procedures $(n=1509)$ : & n $(\%)$ & Hospital mortality - n ( \%) \\
\hline Isolated ASD II closure & $649(43.0 \%)$ & $1(0.2 \%)$ \\
\hline AoV replacement & $111(7.4 \%)$ & $2(1.8 \%)$ \\
\hline Partial AVSD correction & $98(6.5 \%)$ & - \\
\hline VSD closure & $96(6.3 \%)$ & $1(1 \%)$ \\
\hline PAPVC correction & $93(6.1 \%)$ & $1(1 \%)$ \\
\hline Coarctation of the aorta repair & $54(3.6 \%)$ & - \\
\hline RVOTO correction & $52(3.4 \%)$ & - \\
\hline Ross operation & $51(3.4 \%)$ & - \\
\hline Subaortic stenosis resenction & $48(3.2 \%)$ & $1(2 \%)$ \\
\hline Tetralogy of Fallot correction & $37(2.5 \%)$ & $2(5.4 \%)$ \\
\hline Mitral valve replacement/plasty & $37(2.5 \%)$ & - \\
\hline Total cavopulmonary connection & $36(2.4 \%)$ & $3(8 \%)$ \\
\hline Ebstein's tricuspid valve plasty & $19(1.3 \%)$ & - \\
\hline PDA closure & $10(0.7 \%)$ & - \\
\hline Supravalvar aortic stenosis correction & $6(0.3 \%)$ & - \\
\hline Other corrections $^{a}$ & $94(6.4 \%)$ & $7(7.4 \%)$ \\
\hline Main reoperations $(n=464)$ : & n $(\%)$ & Hospital mortality - n ( $\%)$ \\
\hline Conduit placement & $123(26.5 \%)$ & $4(3.1 \%)$ \\
\hline Conduit reoperation & $67(14.4 \%)$ & - \\
\hline Pulmonary valve placement & $45(9.8 \%)$ & $1(2.2 \%)$ \\
\hline Aortic valve replacement & $35(7.6 \%)$ & - \\
\hline Residual VSD closure & $19(4.1 \%)$ & $1(5.2 \%)$ \\
\hline RVOTO reoperation & $19(4.1 \%)$ & - \\
\hline Subaortic stenosis resection & $18(3.9 \%)$ & - \\
\hline Mitral valve replacement & $16(3.5 \%)$ & - \\
\hline Pacemaker implantation & $16(3.2 \%)$ & - \\
\hline Heart transplantation & $15(3.2 \%)$ & $7(46 \%)$ \\
\hline Ross operation & $11(2.3 \%)$ & - \\
\hline Isthmic aortic coarctation redo & $11(2.3 \%)$ & - \\
\hline Mitral valvuloplasty & $9(2.0 \%)$ & $1(11 \%)$ \\
\hline Total cavopulmonary connection & $9(2.0 \%)$ & $1(11 \%)$ \\
\hline Tricuspid valve placement & $8(1.7 \%)$ & - \\
\hline Other reoperations & $43(9.4 \%)$ & $3(6.9 \%)$ \\
\hline
\end{tabular}

a Other diagnoses or surgical treatments not listed in the table included diagnostic of surgical groups of single or few patients.

$\mathrm{AoV}=$ aortic valve; $\quad$ ASD II $=$ ostium secundum atrial septal defect; $\quad$ AVSD = atrioventricular septal defect; $\quad$ BCPS = bidirectional cavopulmonary shunt; DORV $=$ double outlet right ventricle; MAPCAs = main pulmonary artery collaterals from aorta; MV $=$ mitral valve; $\quad \mathrm{PA}=$ pulmonary atresia; $\quad \mathrm{PAPVC}=$ partial anomalous pulmonary venous connections; $\quad \mathrm{PDA}=$ patent ductus arteriosus; $\quad \mathrm{PV}=$ pulmonary valve; RV-MPA = right ventricle-to-main pulmonary artery; RVOTO = right ventricle outflow tract obstruction; TGA = transposition of the great arteries; VSD = ventricular septal defect.

arrhythmias were present in the remaining 199 patients $(9.9 \%)$ and included the following: (1) atrial fibrillation in 106 patients $(53.3 \%)$; (2) III degree AV block in 44 patients $(22.1 \%)$; (3) supraventricular tachycardia in 21 patients $(10.6 \%)$; (4) atrial flutter in 15 patients (7.5\%); and (5) other arrhythmias in 13 patients $(6.5 \%)$. Twenty-two patients had a previous pacemaker implantation.

Preoperative variables which are commonly associated to an increased hospital morbidity and mortality were identified in 397 patients $(19.7 \%)$, being multiple in 150 patients $(37.7 \%)$. Preoperative cyanosis (247 patients, $12.3 \%)(p<0.0001)$, preoperative arrhythmias (199 patients, $9.9 \%)(p<0.03)$, and preoperative NYHA class III and IV $(<0.0001)$ were the only causes linked to an increased hospital mortality. The principal basic diagnoses and diagnoses leading to surgery according to surgical category (ie, palliative procedures, corrective procedures, or reoperations), are presented in Tables 1 and 2 . Listed in 
Table 4. Postoperative Complications

\begin{tabular}{lr}
\hline Complication & $\mathrm{n}$ \\
\hline Arrhythmias & 154 \\
Bleeding & 63 \\
Low output syndrome & 42 \\
Pericardial effusion requiring drainage & 35 \\
Pleural effusion & 35 \\
Pneumothorax & 32 \\
Reoperation during same admission & 29 \\
Mechanical ventilation $\geq 7$ days & 25 \\
Third degree atrioventricular block requiring & 22 \\
permanent pace maker & \\
Wound infection & 22 \\
Pneumonia & 19 \\
Postoperative septicemia & 19 \\
Neurological deficit persisting at discharge & 19 \\
Renal failure & 17 \\
Tracheostomy & 12 \\
Laryngeal nerve injury & 8 \\
Cardiac arrest & 6 \\
Phrenic nerve injury & 6 \\
Other postoperative complications & 19 \\
\hline
\end{tabular}

Table 3 are the main surgical procedures within their respective surgical categories. One-fourth of the patients (528 of 2,012, 26.2\%) required additional surgical procedures: 504 for intracardiac anomalies $(95.4 \%)$ and 24 for extracardiac anomalies (4.6\%). Intraoperative atrial ablation was performed concomitantly in 42 patients $(2 \%)$, while 3 patients required a positioning of an internal cardiac defibrillator. A pacemaker implantation was necessary in 38 patients $(1.9 \%)$.

Major postoperative complications occurred in 444 patients $(22 \%)$. One hundred eighteen patients $(5.9 \%)$ presented multiple complications (Table 4 ). There were 40 hospital deaths $(2 \%)$. The most common causes were the following: (1) sepsis (13 patients, 32.5\%); (2) low cardiac output syndrome (12 patients, 30\%); followed by (3) arrhythmia (7 patients, $17.5 \%$ ); (4) perioperative bleeding (5 patients, $12.5 \%$ ); and (5) neurological events (3 patients, $7.5 \%$ ). Mortality was lower for corrective procedures $(1.2 \%)$ when compared with reoperations $(4.4 \%)$ and with palliative procedures $(7.7 \%)$

At the time of hospital discharge, $92 \%$ of the survivors were in sinus rhythm (1,813 of 1,972 patients). Postoperative arrhythmias were present in the remaining 159 patients $(8 \%)$, of which 109 were untreated arrhythmias and 55 new-onset arrhythmias. They included atrial fibrillation in 76 patients $(47.8 \%)$, third degree AV block in 64 patients $(40.2 \%)$, atrial flutter in 7 patients $(4.4 \%)$, and other arrhythmias in 12 patients $(7.6 \%)$.

Regarding surgical categories, most of the procedures were corrective procedures (1,509 patients, $75 \%)$, followed by reoperations (464 patients, $23.1 \%$ ), and palliative procedures (39 patients, $1.9 \%$ ). Patients who underwent corrective procedures presented with a significantly lower mortality rate $(p=0.001)$ requiring also less time in the intensive care unit $(p=0.002)$ and a shorter total hospital stay $(p=0.0001)$ (Table 5).

Six hundred forty-nine patients underwent isolated ASD II closure $(32.2 \%)$, while 1,363 patients $(67.8 \%)$ required surgical treatment for all other CHD. Patients who underwent isolated ASD II closure had a less complicated postoperative course, requiring less time in the intensive care unit $(p<0.0001)$ and a shorter total hospital stay $(p<0.0001)$ with a hospital mortality of $0.2 \%$. Nonetheless, even after eliminating patients who underwent isolated ASD II closure, the overall mortality of the remaining 1,324 patients was still low (2.9\%).

Follow-up data were available in 1,342 of 1,972 patients $(68 \%)$ who were discharged from the hospital. Fourteen European centers provided us with follow-up data, which was $91 \%$ completed. Five European centers could not provide follow-up data but only with operative data. In these centers, patients were referred for surgical treatment and were later followed by the referring physician of peripheral cardiologic units.

Late deaths occurred in 6 patients $(0.5 \%), 2$ of which were not cardiac-related. Reoperation was necessary in 12 of 1,342 patients $(0.9 \%)$, within a mean time of $29.5 \pm$

Table 5. Surgical Categories

\begin{tabular}{|c|c|c|c|c|}
\hline Variables Analyzed & Palliative Procedures & Corrective Procedures & Reoperations & $p$ Value \\
\hline Number of procedures & $39(1.9 \%)$ & $1509(75 \%)$ & $464(23.1 \%)$ & \\
\hline Sex $M / F$ & $20 / 19$ & 778/731 & $207 / 257$ & 0.03 \\
\hline Mean age in years (SD) & $29.48(11.6)^{\mathrm{a}, \mathrm{c}}$ & $36.21(15.1)^{\mathrm{b}}$ & $28.94(10.7)^{\mathrm{c}}$ & $<0.0001$ \\
\hline Preoperative sinus rhythm & $37(94.9 \%)^{\mathrm{b}}$ & $1383(91.7 \%)^{\mathrm{b}}$ & $393(84.7 \%)^{\mathrm{c}}$ & $<0.0001$ \\
\hline Preoperative cyanosis & $35(89.7 \%)^{\mathrm{d}}$ & $143(9.5 \%)^{b}$ & $69(14.9 \%)^{\mathrm{c}}$ & $<0.0001$ \\
\hline Postoperative complications & $20(51.6 \%)^{\mathrm{d}}$ & $312(20.7 \%)^{b}$ & $111(23.9 \%)^{\mathrm{c}}$ & $<0.0001$ \\
\hline Sinus rhythm at discharge & $34(94.4 \%)$ & $1377(92.4 \%)$ & $402(90.3 \%)$ & 0.33 \\
\hline Mean ICU stay/days (SD) & $3.71(4.4)^{\mathrm{c}}$ & $2.31(5.4)^{\mathrm{b}}$ & $3.25(5.6)^{\mathrm{b}}$ & 0.002 \\
\hline Mean hospital stay/days (SD) & $14.17(8.0)^{\mathrm{b}}$ & $10.54(9.0)^{\mathrm{b}}$ & $12.53(9.7)^{\mathrm{c}}$ & 0.0001 \\
\hline Hospital mortality $(\%)$ & $3(7.7 \%)^{\mathrm{c}}$ & $18(1.2 \%)^{\mathrm{b}}$ & $19(4.1 \%)^{\mathrm{c}}$ & 0.0001 \\
\hline
\end{tabular}

${ }^{a}$ In each category in which the $p$ value is significant, those values with different letters (b, c, and d) are statistically significantly different in the multiple comparison (Tukey) test $(p<0.05)$. 


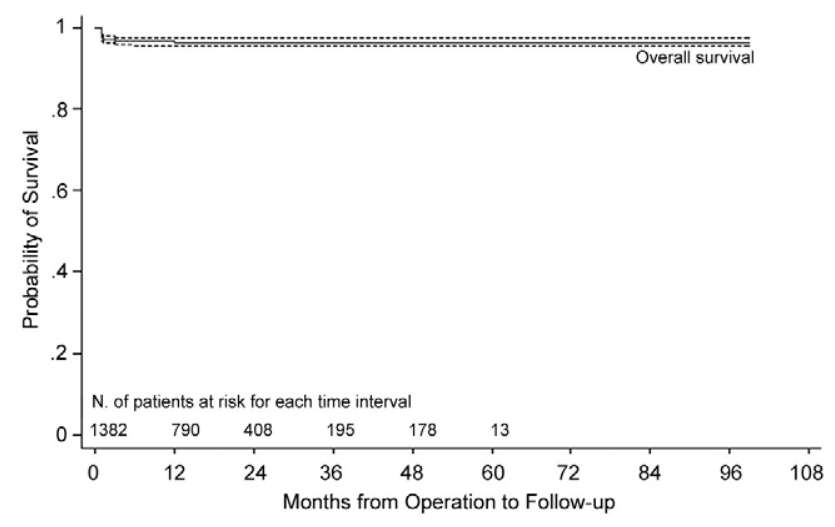

Fig 1. Overall survival probability according to the Kaplan-Meier function with $95 \%$ confidence bands.

12.56 months after hospital discharge. At a mean follow-up time of $18.5 \pm 15.1$ months, 1,041 of 1,257 patients $(77.7 \%)$ belonged to NYHA class I, 265 in NYHA class II $(19.7 \%), 29$ in NYHA class III $(2.2 \%)$, and 6 in NYHA class IV $(0.4 \%)$. There was a statistical significant change of the NYHA status $(p<0.001)$ between the preoperative period and the last follow-up control (mean follow-up time of $18.5 \pm 15.1$ months). The median change is a decrease of one category.

Survival probability according to Kaplan-Meier showed an overall survival of $97 \%$ at 60 months (Fig 1). According to surgical categories, survival probability at 60 months is higher for corrective procedures $(98.2 \%)$ if compared with reoperations $(94.1 \%)$ or palliative procedures $(86.1 \%)$ (Fig 2$)(p<0.0001)$. Survival probability at 60 months after surgery for patients who required surgical closure of an isolated ASD II was $99.1 \%$. Excluding the ASD II group of patients, the survival at 60 months for all other patients requiring surgical treatment was $95.5 \%$ (Fig 3) $(p<0.0001)$.

\section{Comment}

This study aims to assess the risks of cardiac surgery for CHD in patients of age 18 years or greater, treated in 19

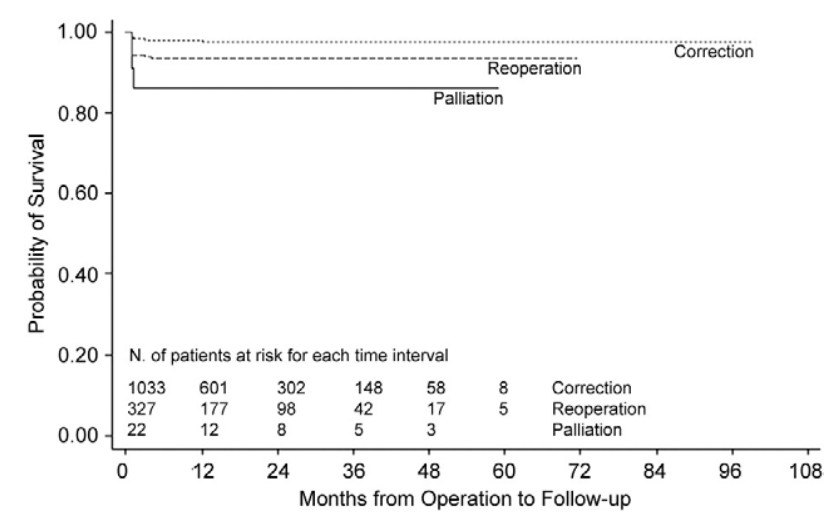

Fig 2. Kaplan-Meier survival function by type of surgery (palliations, corrections, reoperations).

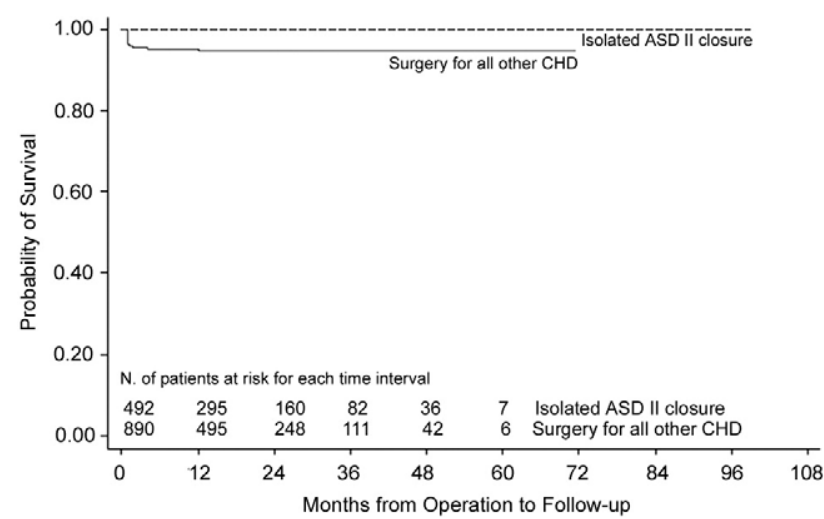

Fig 3. Kaplan-Meier survival function by ostium secundum atrial septal defect (ASD II) versus surgery for all other congenital heart disease (CHD).

different cardiac units in Europe. The number of adult patients with congenital heart disease, treated and untreated, has been growing steadily since the 1960s due to the increasing optimization of surgical and medical treatment. According to Webb [6] the number of adult patients with CHD will be roughly equal in the next few years to those in pediatric age.

Surgery for CHD in adults is mostly indicated to hopefully prolong the patient's life expectancy and to improve lifestyle. While the natural history of CHD in children is reasonably well known, the natural history of adult patients with CHD is less well documented $[3,5]$.

Patients with CHD who reach the adult age usually remain in good or mildly decreased functional status for several years and are eventually referred to surgical treatment because of increasing symptoms not controlled by medical therapy $[2,17-20]$. They are a selected group of patients mainly composed by individuals who have survived into adult age without irreversible damage to their heart and lung, or with previously undetected CHD who remained asymptomatic during childhood, or who require reoperations because of late complications or residual defects, after initial surgical treatment in the childhood. Surgical outcome for these patients is satisfactory if treatment is performed before irreversible damage has occurred to the heart and lungs [3, 17]. This assertion is supported by finding in this study, confirming also that a decreased functional status (NYHA class III-IV) and exposure to prolonged cyanosis proved to be significant risk factors for an operative mortality.

A palliative procedure was offered to an adult patient with complex CHD with the hope to at least temporarily improve the clinical condition. Although the palliative operations in these kinds of patients did achieve a decrease on cyanosis at low risk (hospital mortality of $7.7 \%$ ), we have no long-term functional results of these patients to allow definitive conclusions.

Reoperation after a previous corrective procedure also carried a low hospital mortality $(4.1 \%)$. This group includes patients with either a residual lesion after correction or patients who acquired secondary complications 
after their initial correction, and including mainly conduit placement-change (190 of 464 patients, 41\%), pulmonary valve change (45 of 464 patients, 10\%), and aortic valve replacement (35 of 464 patients, $7.5 \%$ ). The relative low percentage of reoperations $(23.1 \%)$ among all surgical procedures could be justified by the increasing number of interventions in the catheterization laboratory (such as for atrial septal defect closure, radiofrequency ablation, pacemaker implantation, etc). As a consequence the number of patients with a residual isolated ASD II could also be underestimated. In fact, many patients could probably have been referred for percutaneous transcatheter treatment after surgery and therefore not entered in our surgical database.

A follow-up analysis shows an overall survival probability of $97 \%$ at 60 months, which is higher for corrective procedures $(98.2 \%)$ if compared with reoperations $(94.1 \%)$ and palliations $(86.1 \%)$. Survival probability of patients requiring closure of an isolated ASD II is $99.1 \%$ at 60 months. After excluding the ASD II patients, survival rate at 60 months for all other patients was still $95.5 \%$.

The majority of these patients survived into adult age ( $\geq 18$ years) in good functional status, considering that $77.2 \%$ of them was in preoperative NYHA class I or II. Our data suggest that an adult congenital patient is treated early in his clinical presentation (NYHA class I-II), the hospital outcome can be better when compared to that of patients who presented with worst functional status (NYHA class III-IV) with a significant increase in functional status at midterm survival: 1,306 of 1,342 patients $(97.4 \%)$ who were discharged from the hospital were in NYHA class I-II at the $18.5 \pm 15.1$ months last follow-up control ( $p<0.001)$.

Obviously, long-term postoperative functional results of these patients are extremely important to know, unfortunately we were able to collect follow-up information only in $68 \%$ of the patients and limited to 60 months after the operations (mean of $18.5 \pm 15.1$ months). The main reason for this limitation of this study was that most of the patients were referred to the tertiary centers for surgical treatment and were later followed by the referring physician of peripheral cardiologic units. According to that, believing that tertiary units have the duty to find out what happens to the patients referred to them for surgery, we are now developing an educational program with the aim to involve peripheral unit in our data collection.

According to our data, surgical treatment of CHD in adults when performed in specialized European cardiac facilities, proved to be quite safe, beneficial, and low risk. We believe that a $2 \%$ hospital mortality in our study population compared well with the $5 \%$ mortality rate from the European Congenital Database [19-25]. It is obvious that in the adult population we do not encounter very complex $\mathrm{CHD}$; ie, hypoplastic left heart syndrome, complex functional single ventricle malformations, heterotaxia syndrome, etc.

The low mortality for adult patients who require surgery for CHD, when compared with the pediatric population, may be attributable to the high level of specializa- tion coming from the pediatric cardiac units participating in the study. In fact, the care of adult patients with corrected or uncorrected CHD is growing and already is a challenging new field in cardiology. It requires knowledge of the following: (1) pathology of congenital cardiac malformations; (2) treatment options (ie, surgery versus interventional cardiology; (3) postoperative cardiac and noncardiac complications and sequelae; (4) acquired cardiac and noncardiac diseases that appear with age; and eventually, according to the high incidence of preoperative and postoperative arrhythmias (5) the need for expertise in electophysiology $[3,17,18]$. To address the many different needs of this complex and growing patient population, and in order to have a good outcome, this complex group of patients with CHD should be addressed to these units, and also new specialized units are needed around the world [26-27].

Furthermore, while a risk-adjusted method for surgery of acquired heart diseases and surgical treatment of pediatric patients with congenital heart disease have been well established and refined over the last 10 years, [28-31], a risk-adjusted model to predict in-hospital mortality for adult patients with CHD is still lacking. This will be of fundamental importance to allow a meaningful comparison and to evaluate surgical risks of this emerging group of patients.

We thank Dr Aldo Castañeda for reviewing our manuscript. This work has been undertaken under the aegis of the European Congenital Heart Surgeons Association (ECHSA).

\section{References}

1. Warnes CA, Somerville J. Tricuspid atresia with transposition of the great arteries in adolescents and adults: current state and late complications. Br Heart J 1987;57:543-7.

2. Berdat PA, Immer F, Pfammatter JP, Carrel T. Reoperations in adults with congenital heart disease: analysis of early outcome. Int J Cardiol 2004;93:239-45.

3. Williams WG, Webb GD. The emerging adult population with congenital heart disease. Semin Thorac Cardiovasc Surg Pediatr Card Surg Annu 2000;3:227-33.

4. Monro J. The changing state of surgery for adult congenital heart disease. Heart 2005;91:139-40.

5. Stellin G, Vida VL, Padalino MA, Rizzoli G. Surgical outcome for congenital heart malformations in the adult age: a multicentric European study. Semin Thorac Cardiovasc Surg Pediatr Card Surg Annu 2004;7:95-101.

6. Webb GD. Care of adults with congenital heart diseases-a challenge for the new millenium. Thorac Cardiovasc Surg 2001;49:30-4.

7. Niwa K, Perloff JK, Webb GD, et al. Survey of specialized tertiary care facilities for adults with congenital heart disease. Int J Cardiol 2004;96:211-6.

8. Hannoush H, Tamim H, Younes $\mathrm{H}$, et al. Patterns of congenital heart disease in unoperated adults: a 20 -year experience in a developing country. Clin Cardiol 2004;27:236-40.

9. Somerville J. Management of adults with congenital heart disease: an increasing problem. Annu Rev Med 1997;48:28393.

10. Sarris GE, Giannopoulos NM, Tsoutsinos AJ, et al. Result of surgery for Ebstein's anomaly: a multi-center study from the European Congenital Heart Association. J Thorac Cardiovasc Surg 2006;132:50-7. 
11. Sarris GE, Chatzis AC, Giannopoulos NM, et al. The arterial switch operation in Europe for transposition of the great arteries: a multi-institutional study from the European Congenital Heart Surgeons Association. J Thorac Cardiovasc Surg 2006;132:633-9.

12. Maruszewski B, Tobota Z. The European Congenital Heart Defects Surgery Database experience: Pediatric European Cardiothoracic Surgical Registry of the European Association for Cardio-Thoracic Surgery. Semin Thorac Cardiovasc Surg Pediatr Card Surg Annu. 2002;5:143-7.

13. Maruszewski M, Lacour-Gayet F, Monro JL, Keogh BE, Tobota Z, Kansy A. An attempt at data verification in the EACTS Congenital Database. Eur J Cardiothorac Surg 2005; 28:400-4; discussion 405-6.

14. EACTS congenital database. Available at: http://www. eactscongenitaldb.org/index.php? $\mathrm{LANG}=$ en\&level $=1$ \&struct $=1$ (accessed July 15, 2006).

15. Joffs C, Sade RM. Congenital heart surgery nomenclature and database project: palliation, correction, or repair? Ann Thorac Surg 2000;69:S369-72.

16. Glantz S. Primer of biostatistics. Fifth ed. New York: McGraw-Hill, 2002.

17. Dore A, Glancy DL, Stone S, Menashe VD, Somerville J. Cardiac surgery for grown-up congenital heart patients: survey of 307 consecutive operations from 1991 to 1994. Am J Cardiol 1997;80:906-13.

18. Gazoulis MA, Hechter S, Webb GD. Outpatients for adults with congenital heart disease: increasing workload and evolving patterns of referral. Heart 1999;81:57-61.

19. Lacour-Gayet F, Clarke D, Jacobs J, et al. The Aristotle score for congenital heart surgery. Semin Thorac Cardiovasc Surg Pediatr Card Surg Annu 2004;7:185-91.

20. Lacour-Gayet F, Clarke D, Jacobs J, et al. The Aristotle score: a complexity-adjusted method to evaluate surgical results. Eur J Cardiothorac Surg 2004;25:911-24.

21. Jacobs JP, Ungerleider RM, Tchervenkov CI, et al. Opinions from the audience response survey at the first joint meeting of the Congenital Heart Surgeons' Society and the European Congenital Heart Surgeons Association. Semin Thorac Cardiovasc Surg Pediatr Card Surg Annu 2005;14:198-217.
22. Jacobs JP, Lacour-Gayet F, Jacobs ML, et al. Initial application in the STS congenital database of complexity adjustment to evaluate surgical case mix and results. Ann Thorac Surg 2005;79:1635-49; discussion 1649.

23. Jacobs JP, Maruszewski B. European Association for Cardiothoracic Surgery--Society of Thoracic Surgeons Joint Congenital Heart Surgery Nomenclature and Database Committee. Computerized outcomes analysis for congenital heart disease. Curr Opin Pediatr 2005;17:586-91.

24. Jacobs LP, Jacobs ML, Maruszewski B, et al. Current status of the European Association for Cardio-Thoracic Surgery and the Society of Thoracic Surgeons Congenital Heart Surgery Database. Ann Thorac Surg 2005;80:2278-83; discussion 2283-4.

25. Jacobs JP, Mavroudis C, Jacobs ML, et al. What is operative mortality? Defining death in a surgical registry database: a report of the STS Congenital Database Taskforce and the Joint EACTS-STS Congenital Database Committee. Ann Thorac Surg 2006;81:1937-41.

26. Bhat $\mathrm{AH}$, Sahn DJ. Congenital heart disease never goes away, even when it has been "treated": the adult with congenital heart disease. Curr Opin Pediatr 2004;16:500-7.

27. Srinathan SK, Bonser RS, Sathia B, Thorne SA, Brawn WJ, Barron DJ. Changing practice of cardiac surgery in adult patients with congenital heart disease. Heart 2005;91:139 140.

28. Shroyer AL, Coombs LP, Peterson ED, et al. The Society of Thoracic Surgeons: 30-day operative mortality and morbidity risk models. Ann Thorac Surg 2003;75:1856-65.

29. Nashef SA, Roques F, Hammill BG, et al. Validation of European system for cardiac operative risk evaluation (Euro-SCORE) in North American cardiac surgery. Eur J Cardiothorac Surg 2002;22:101-5.

30. Jenkins KJ. Risk adjustment for congenital heart surgery: the RACHS-1 method. Semin Thorac Cardiovasc Surg Pediatr Card Surg Annu 2004;7:180-4.

31. Lacour-Gayet F. Risk stratification theme for congenital heart surgery. Semin Thorac Cardiovasc Surg Pediatr Card Surg Annu 2002;5:148-52. 